\title{
Annals of Surgery
}

Vol.r XLIII

JANUARY, 1906

No. I

\section{ORIGINAL MEMOIRS.}

\section{ON PRESERVATION OF THE NERVE SUPPLY TO THE BROW, IN THE OPERATIVE APPROACH TO THE GASSERIAN GANGLION.}

\section{BY HARVEY CUSHING, M.D.,}

OF BALTIMORE.

JUDGING from the photographs that have accompanied the reports of cases operated upon by others, as well as from my own experience with the ganglion operation, an almost inevitable effect of the incision, as it is usually made, is a paralysis of the occipitofrontalis muscle (pars frontalis) due to the severance of the upper twig of the facial nerve. This highest branch of the "Pcs anscrinus" after crossing the zygoma on its way to the brow takes its course through the subcutaneous tissue overlying the temporal fossa, and thus traverses the direct field of approach to the ganglion. Just below and in front of it lies a separate branch destined to innervate the orbicularis, and some of the proposed methods of approaching the intracranial field of operation must necessarily sacrifice both of these upper twigs of the facial, and so lead not only to the deformity under discussion, but to impairment of the palpebral sphincter as well,-a matter of no small moment. It is 
exceptional, however,-though the accident has been known to occur,-for the lower of these nerves to be injured either by the Hartley-Krause procedure or by the modification of their method which I have favored. Section of the upper twig, on the other hand, can hardly be avoided in making the ustral horseshoe-shaped incision so commonly employed. Heretofore, so far as I am aware, no effort has been macle to preserve this nerve; the operation in itself being considered so serious a one that such a trifling postoperative palsy as results from its division has hardiy seemed deserving of attention. The deformity is not an obtrusive one, only showing when there is an effort to raise the eyebrows, or in old people by a planing out of the transverse folds of the brow on the side of the neurectomy (Fig. 1). Nevertheless, as an operation develops, it is well to improve its technique even in the smallest details, and a modification of any operative procedure which can, even in slight degree, improve its cosmetic result, is most desirable, and this is especially so when a palsy of the expressional musculature is concerned.

In a recently printed paper dealing with this operation,* comment was made upon this slight paralysis, and the opinion was expressed that an effort to save this small nerve would so further complicate an already complicated operation that the attempt would be injudicious. It was also noted that in a few of the cases of my series there had been a partial restoration of the power. to elevate the brow, due, it was presumed, to the painstakingly exact approximation of all the divided tissues at the time the wound was closed. For, if unnecessary scar formation or the interposition of other tissue does not prevent, there is a natural tendency on the part of severed peripheral nerves to reunite and to re-establish connection with their old terminals. In the case, however, of such a long and delicate nerve as that under discussion, this good fortune can rarely be expected.

* "The Surgical Aspects of Major Neuralgia of the Trigeminal Nerve." Journal of the American Medical Association, March-April, 1905. 


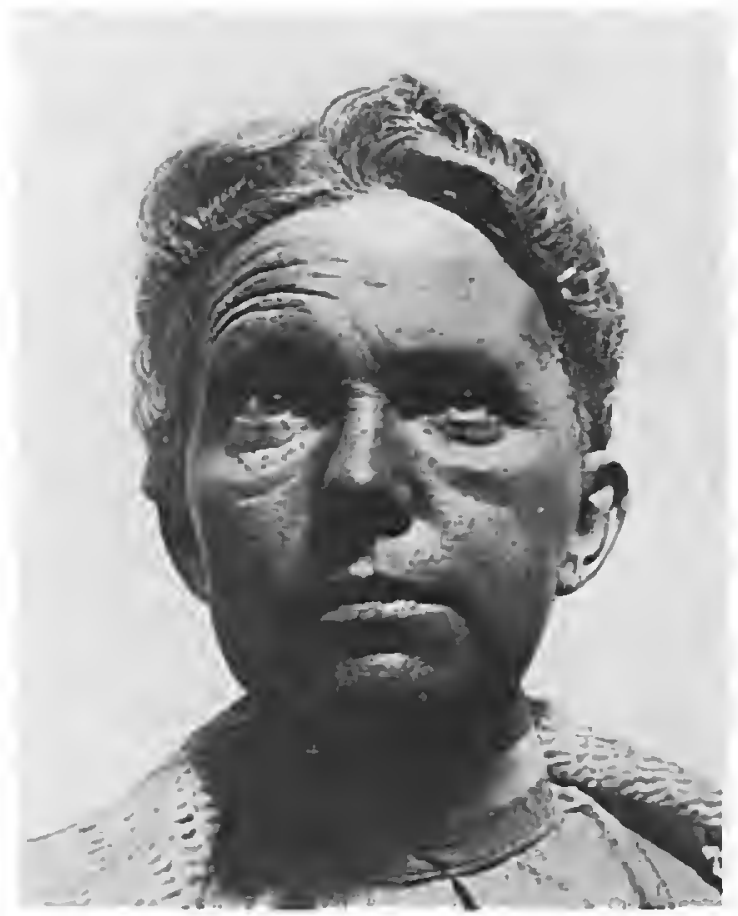

Fyc. $t$ - Photograph of a patient in whom the bighest branch of the facial ou the left side has been dividerl, as in the usual temporal iucision; to show the deformity under discussion. Note the sagging of the brow on the left side and absence of frontal wrinkles during the effort to look upwarel. 


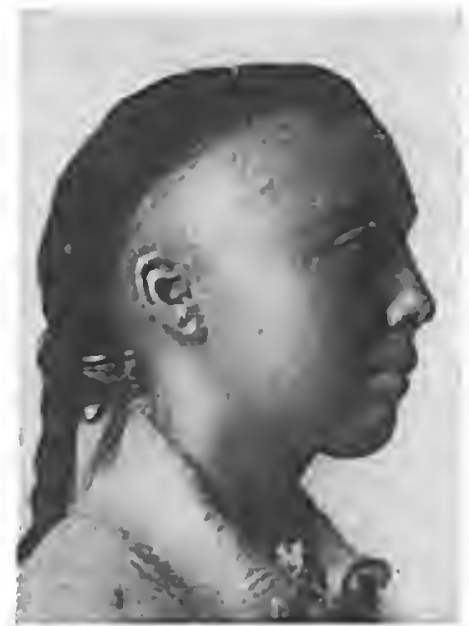

Fig. 2. -To show line of incision. I'hotograph taken on fifth day after operatiou. All sutures were removed on the second day, except the inost anterior one: as scar was alinost invisible this one was left to delinit anterior end of incision fn photograph. Nodraiunge used.

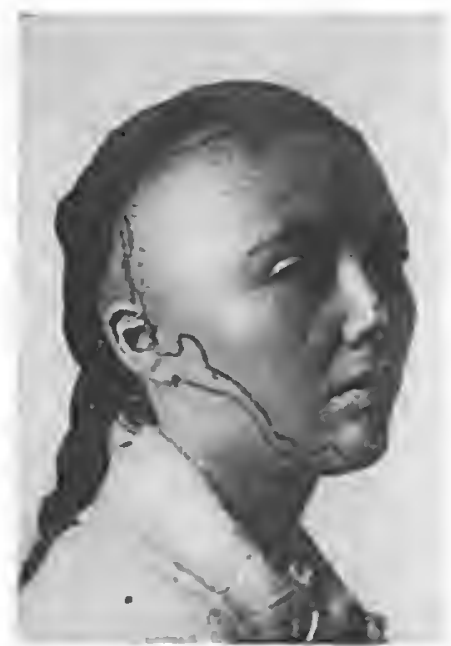

Ftu 3.-l'ostoferative areas of andesthesia; total within inner line. Scars of earliet periphersil operation observahle under eye and angle of jaw. 


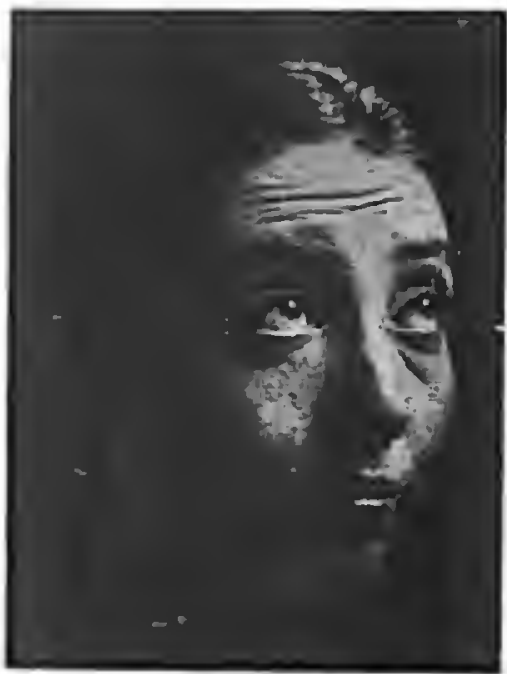

Hic. 4.-T wo weeks after operation. Almost total restoration of movement of occipjic frontalis, temporarily paralyzed in this case.

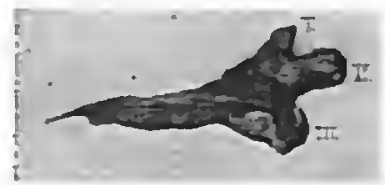

Fiti. 5. - l'horograph of tissues removed; showing intracranial portion of the fifth nerve iutact. Slightly reduced in size. Under suriace of ganglioı. 
In my last five operations I have again turned my attention to the question of preserving this nerve, and have found, contrary to my expectations, that the incision and approach to the skull could be so altered as to avoid injuring it without adding particular difficulties to or modifying in any great respect the subsequent steps of the operation. Four of these cases have been total extirpations for major neuralgia; in the fifth I had to be satisfied with simple division of the sensory root of the trigeminus,-a case in which an inoperable sarcoma had grown up through the base of the skull under the ganglion, causing severe trigeminal pain. The malignant nature of the disease from which this patient was suffering rendered the question of cosmetic result far less important than in the neuralgia cases, and consequently the zygomatic arch was not removed, but in other respects the method of approaching the ganglion has been the same in each of the five cases.

The situation of the incision can be seen by consulting the accompanying photographs of one of the patients. It has been made within the hair margin, not for the purpose of concealing the scar, because these cicatrices are almost invisible after the operation, but, as has been stated, in orcier to avoid division of the nerve. The posterior limb of the incision is carried down to the zygoma over the temporal vessels, which usually must be ligated. The skin flap is then reflected downward and forward by blunt dissection, the handle of the scalpel sufficing for this purpose. The temporal fascia, thus exposed, is incised in a line concentric with the skin incision and likewise reflected. The zygoma, which has thus been brought into view at the lower angle of the wound, is then shelled out of its periosteal sheath, not as formerly described by making an incision along its external surface, but by crowding forward its coverings en masse. The exposed fibres of the temporal may then be divided as usual by a horseshoe-shaped incision, and the muscle scraped away with a periosteal elevator as far down as the base of the skull. In order to satisfactorily expose the skull, a little deeper retraction of the flap is necessary than by the older metlod, the ordinary small appendix retractor 
being used for the purpose of holding down the cutaneous and fascial part of the flap as well as the muscle. From this point on the operation is conducted as heretofore described.

In the first of these cases, when the skin flap had been retracted, the nerve to the brow was exposed, and, though efforts were made to preserve it, it doubtless suffered injury through stretching during the downward retraction of the flap in the subsequent stages of the ganglion extirpation. Immediately after the operation it was found that the customary inability to elevate the brow was present; but the paralysis was of short duration, and before the patient was discharged from the hospital two weeks later, it had so far recovered that almost a symmetrical wrinkling of the two sides of the forehead was possible (Fig. 3).

In the other four patients even this temporary palsy of the nerve was avoided, and the cases are so much alike that it is needless to give more than this one series of photographs to show the situation of the incision, which did not interfere with subsequent innervation of the occipitofrontalis, and at the same time allowed sufficient access to the ganglion to insure a total extipation. 